\title{
A BRIEF AND SPECIFIC REVIEW ON THE UTILITY OF SURFACE FUNCTIONALIZED MAGNETITE NANOPARTICLES FOR THE REMOVAL OF DYE FROM CONTAMINATED WATER
}

\author{
A. Jangra ${ }^{1}$, P. Kumar ${ }^{1}$, R. Khanna ${ }^{2}$, A. Chaudhary ${ }^{1}$, S. Kumar ${ }^{1}$, \\ J. Singh ${ }^{1}$ and R. Kumar, ${ }^{1} \bowtie$ \\ ${ }^{1}$ Department of Chemistry, Kurukshetra University, Kurukshetra-136119, (Haryana) India \\ ${ }^{2}$ Department of Chemistry, Babu Anant Ram Janta College, Kaul-136021 \\ ${ }^{\square}$ Corresponding Author: rameshkumarkuk@gmail.com
}

\begin{abstract}
A large amount of synthetic dyes is being produced worldwide and a significant amount of these dyes are consumed in various industries like textiles, leather, cosmetics, plastic, paper, printing, pharmaceutical, food industries and many more. The processed water streams containing dyes as major contaminants are discharged into water bodies leading to water pollution. Therefore, the exclusion of these dyes from the industrial streams is essential for the water remediation and the subsistence of aquatic life. Nanoparticles are being used for the degradation of dye effluents from polluted water. Though, the surface-functionalized magnetite nanoparticles have drawn the attention of the scientists. This review article covers the utility of the only surface-functionalized magnetite nanoparticles for the sorption of colored effluents from polluted water.

Keywords: Polluted Water, Dyes, Magnetite Nanoparticles, Surface Functionalization
\end{abstract}

RASĀYAN J. Chem., Vol. 14, No.2, 2021

\section{INTRODUCTION}

Water is the basic requirement for the subsistence of human beings and all other animals. However, the water is being contaminated day by day due to increasing population and industrialization. The pollution of water with chemical and biological pollutants has become a severe problem in modern times. The discharge of industrial wastewater containing dye contaminants to the water bodies also contributes to water pollution in a significant proportion. Some of the dyes are highly toxic and can enter into the bodies of human beings and other animals via the food chain ${ }^{1}$. Therefore, water detoxification becomes important to avoid the adverse effects of the pollutants. Some methods used for water detoxification are adsorption, ion exchange, filtration and reverse osmosis. Besides this, coagulation-flocculation, precipitation, evaporation, oxidation and biosorption method have also been adopted ${ }^{2}$. In this context, nanotechnology offers effective tools for the efficient removal of toxins and contaminants from the wastewater. These tools include nanoparticles, nanopowder and nanomembrane, which can be used for the removal of toxic chemical substances like dyes and metal ions. However, due to commercial and ecological factors, evacuation of dyes from the water using surface-functionalized magnetite nanoparticles has gained more attention ${ }^{3}$. Numerous researchers have already studied the synthesis, benefits and detriments of surface-modified nanoparticles ${ }^{4}$. In this review article, the work published on the use of functionalized magnetite nanoparticles specifically for the separation of dyes from the wastewater has been summarized.

\section{Magnetite Nanoparticles (MNPs)}

Iron oxide nanoparticles (IONPs) are small particles of the iron oxides having nanoscale sizes i.e. from $1 \mathrm{~nm}$ to $100 \mathrm{~nm}$. The most extensively studied IONPs include magnetite $\left(\mathrm{Fe}_{3} \mathrm{O}_{4}\right)$ and maghemite $\left(\gamma-\mathrm{Fe}_{2} \mathrm{O}_{3}\right)$ nanoparticles. Among these IONPs, magnetite nanoparticles are extensively studied due to their unique properties. In the present study, the use of surface-functionalized magnetite nanoparticles has been stated Rasayan J. Chem., 14(2), 829-835(2021) 
for the degradation of dye contaminants from the wastewater due to their biocompatibility and magnetic character $^{5}$. Moreover, magnetite nanoparticles show superparamagnetism; a state of zero magnetization without applying an external magnetic field.

\section{Methods for Preparation of Magnetite Nanoparticles (MNPs)}

Several methods for the synthesis of magnetic nanoparticles have been described in the literature. Coprecipitation, micro-emulsion and hydrothermal methods are the most popular methods being adopted for the synthesis of MNPs. Out of these, the co-precipitation method is possibly the simplest and costeffective pathway to synthesize MNPs in good yield. The size and shape of the MNPs generally depend upon many factors including the types of iron salts used and the $\mathrm{pH}$ of the medium. In the co-precipitation method, ferrous and ferric salts (2:1 molar ratio) are dissolved in deionized water and heated in an oxygen-free environment ${ }^{6}$. Finally, the $\mathrm{pH}$ is raised to $\sim 9-10$ by the addition of $\mathrm{NH}_{4} \mathrm{OH}$ to give a black precipitate of MNPs.

$$
\mathrm{Fe}^{2+}+2 \mathrm{Fe}^{3+}+8 \mathrm{OH}^{-} \underset{\mathrm{pH}=9.0,80^{\circ} \mathrm{C}}{\stackrel{\text { Oxidation, Dehydration }}{\longrightarrow}} \mathrm{Fe}_{3} \mathrm{O}_{4}+4 \mathrm{H}_{2} \mathrm{O}
$$

Another common method used for the preparation of MNPs is microemulsion method such as cyclohexane was used as the oil phase while nonoxylnol-9 phosphate and polyoxyethylene isooctyl ether phosphate were treated as the surfactant for the preparation of superparamagnetic MNPs ${ }^{7}$. $\mathrm{FeSO}_{4} / \mathrm{Fe}\left(\mathrm{NO}_{3}\right)_{3}$ was used as the source of iron. This method has an extra advantage as MNPs don't get agglomerated. However, in this method, the $\mathrm{pH}$ of the reaction mixture affects the morphology of nanoparticles under preparation. In hydrothermal method, MNPs are synthesized by hydrolysis and oxidation reaction followed by the neutralization of mixed metal hydroxides. Contrary to the methods discussed above, in hydrothermal method, only one salt of iron is used. The large-sized MNPs are obtained via this method ${ }^{8}$. Highly crystalline and large-sized MNPs can be synthesized by using hydrothermal method.

\section{Applications of Magnetite Nanoparticles}

Magnetite nanoparticles have unique physical, chemical, mechanical, thermal and magnetic properties. Owing to these properties, the MNPs offer great opportunities to scientists for their use in biomedical and environmental fields. In brief, cellular therapy, hyperthermia, targeted drug delivery are the major biomedical applications of magnetite nanoparticles. Besides this, these nanoparticles can be used as potential MRI contrast agents. As far as environmental applications are concerned, magnetite nanoparticles are used for the purification of wastewater by extracting dyes, heavy metal ions as well as other organic and inorganic contaminants. However, in this review article, the focus will be on new developments in the exclusion of the dye pollutants from the contaminated water using surface-modified MNPs.

\section{Surface Functionalized Magnetite Nanoparticles as Potential Nanoadsorbents}

A variety of traditional adsorbents are available for the degradation of dyes and other impurities from the contaminated water. However, surface tailored MNPs are proven excellent adsorbent tools owing to their exceptional properties i.e. "high surface to volume ratio" and "magnetic character". One of the major advantages of using surface-modified MNPs as nano adsorbents is their easy separation from the water by applying an external magnetic field.

\section{Surface Functionalization of Magnetite Nanoparticles for the Removal of Dyes from Water}

A lot of work has been already reported on the surface functionalization of MNPs using different kinds of coating materials having suitable functional groups [Scheme-1] to enhance the dye removal proficiency from the wastewater. The upcoming sections illustrate the use of various types of compounds for the surface functionalization of magnetite nanoparticles to increase their dye removal efficiency. 
RASĀYAN J. Chem.

Vol. 14 | No. 2 |829-835| April - June | 2021

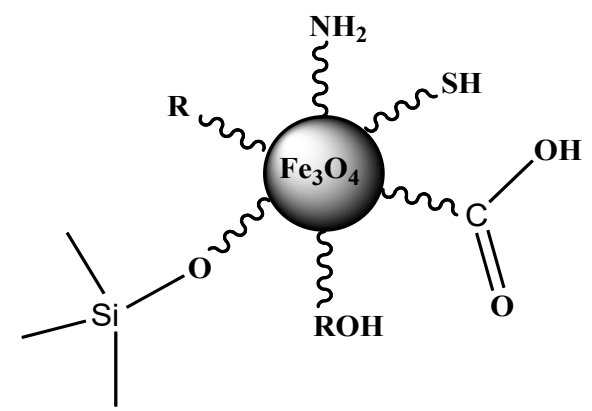

Scheme-1: Schematic Representation of Surface Functionalization of Magnetite Nanoparticles

\section{Surface Functionalization using Organic Molecules}

Coating of organic molecules on the surfaces of inorganic molecules results in the change of their surface/interface properties. So, their properties e.g. adhesion, sensing and catalysis are also affected. Organic molecules used for surface functionalization of MNPs can be divided into two categories i.e. polymeric organic molecules and non-polymeric organic molecules.

\section{Surface Functionalization with Polymeric Organic Molecules}

Due to biocompatibility and high adsorption capacity, polymers are considered a good choice for the surface functionalization of MNPs. For example, polyacrylic acid (PAA) ${ }^{9}$ and poly-glutamic acid (PGA) ${ }^{10}$ modified MNPs have been reported as potential nano adsorbents for the sorption of the colored effluents from the aqueous solution. 3-aminotriethoxysilane and copolymer acrylic acid and crotonic acid (APTESAA@Co@CA) modified magnetite nanoparticles were synthesized and their efficiency to isolate cationic dyes from the aqueous solution was examined ${ }^{11}$. O-carboxymethyl chitosan-n-lauryl functionalized $\mathrm{Fe}_{3} \mathrm{O}_{4}$ nanoparticles were utilized for the adsorption of "Remazol Red 198" dye from water ${ }^{12}$. It was observed that the adsorption process was facilitated to a significant extent with an increase in temperature. The temperature rise caused a swelling effect which favored the dispersion of dye molecules into the inner structure of surface-modified MNPs. Four cycles of adsorption and desorption were performed to evaluate the ability to reuse these surface coated nanoparticles. A noteworthy decrease in adsorption capacity was detected after each cycle. Polymer engineered MNPs for the degradation of dye "Alizarin Red S" from the aqueous solution of different concentrations ${ }^{13}$ was studied. Further, the adsorption capacity of [2(methacryloyloxyl) ethyl] trimethylammoinum chloride (polyMETAC) coated MNPs for dye removal was found in the range of $80-96 \%$. Chitosan, a well-explored polymer, has been used for the surface functionalization of MNPs for the separation of dyes from the water. Chitosan, however, due to some properties like poor mechanical strength and low specific gravity showed limited adsorption capacity. Therefore, to improve its adsorption capacity, chitosan is being used in combination with MNPs. Chitosan-coated MNPs were synthesized which were utilized for the degradation of "Blue 19" dye from the waste water ${ }^{14}$. $\mathrm{pH}$ influences on the adsorption capacity were also investigated. It was perceived that the sorption of dye decreased at low $\mathrm{pH}$. This effect was observed due to variation in solubility of chitosan shells at different $\mathrm{pH}$. Polypyrrole, a polymer having a multifunctional structure, has also been used for the surface modification of MNPs ${ }^{15}$. The percentage removal efficiency of Alizarin Yellow GG (AY) and Alizarin Red-S (AR) dyes was found to be $98 \%$ and $79 \%$, respectively. Poly(styrene-comethacrylic acid) modified the surface of magnetic nanoparticles were synthesized for the separation of "crystal violet" and "Rhodamine B" dyes from the aqueous solution ${ }^{16}$. The desorption study was also explored which suggested the reusable characteristics of these magnetic nanoparticles. Polyethylene glycol (PEG) functionalized $\mathrm{Fe}_{3} \mathrm{O}_{4}$ in combination with $\mathrm{Mg}$-Al-layered double hydroxides were prepared for their utility as adsorbent for the effective degradation of methyl orange dye ${ }^{17}$. Adsorption kinetics studies, along with thermodynamic studies were also investigated. Thermodynamic data indicated the endothermic and spontaneous nature of the process. Moreover, the effect of $\mathrm{pH}$, temperature and dye concentration of methyl orange on adsorption efficiency was also examined. A recent development on the use of polymer-modified magnetic nanoparticles for the deduction of methylene blue from waste water ${ }^{18}$ has been reported. $\mathrm{Fe}_{3} \mathrm{O}_{4} @ \mathrm{SiO}_{2}$-MPS-g-AA-AMPS magnetic nanoparticles were prepared by attaching 
RASĀYAN J. Chem.

Vol. 14 | No. 2 |829-835| April - June | 2021

acrylic acid (AA) and 2-acrylamido-2-methyl-1-propanesulfonic acid (AMPS) over the surface of vinylfunctionalized- $\mathrm{Fe}_{3} \mathrm{O}_{4} @ \mathrm{SiO}_{2}$ core. The study revealed that the adsorption capacity of these magnetic nanoparticles can be enhanced by increasing the concentration of grafting monomer. The overall study validated the fact that these modified magnetic nanoparticles possess great potential to adsorb the methylene blue (MB) dye from wastewater. It was observed that the adsorption capacity of these functionalized MNPs remained more than $60 \%$ even after eight cycles of adsorption and regeneration. Recently, the use of carboxymethyl cellulose was reported for functionalization of magnetic nanoparticles with $\mathrm{Fe}_{3} \mathrm{O}_{4} @ \mathrm{SiO}_{2}$ core-shell for the removal of cationic dye, methylene blue from waste water ${ }^{19}$. Bare magnetite nanoparticles synthesized using the co-precipitation method were silylated $\left(\mathrm{Fe}_{3} \mathrm{O}_{4} @ \mathrm{SiO}_{2}\right)$ followed by their treatment with 3-aminopropyltriethoxysilane (APTES) to form $\mathrm{Fe}_{3} \mathrm{O}_{4} @ \mathrm{SiO}_{2}$-APTES. The surface of $\mathrm{Fe}_{3} \mathrm{O}_{4} @ \mathrm{SiO}_{2}$-APTES was functionalized with biopolymer carboxymethyl cellulose through amide linkage $\left(\mathrm{CMC}\right.$ functionalized $\left.\mathrm{Fe}_{3} \mathrm{O}_{4} @ \mathrm{SiO}_{2}\right)$. In this paper, the effects of several factors influencing the dye removal efficiency of these CMC functionalized $\mathrm{Fe}_{3} \mathrm{O}_{4} @ \mathrm{SiO}_{2}$ were investigated. The overall study suggested that these polymer-modified nanoparticles can be used as a potential tool for the adsorption of methylene blue dye. Lignin biopolymer obtained from green coconut fiber was used for surface functionalization of $\mathrm{Fe}_{3} \mathrm{O}_{4}$ to form lignin/ $/ \mathrm{Fe}_{3} \mathrm{O}_{4}$ nanoparticles ${ }^{20}$. Thus, synthesized nanoparticles demonstrated adsorbent characteristics including low equilibrium time and high proficiency of adsorption for various textile dyes. Lignin-tailored iron oxide nanoparticles were consumed for the degradation of textile dyes including methylene blue, cibacron blue and remazol red.

\section{Surface Functionalization with Non-polymeric Organic Molecules}

Surface functionalization of MNPs with non-polymeric organic molecules for their utilization in dyes removal from the aqueous solution has been widely reported such as surface functionalization of magnetite NPs using organic acids i.e. oleic acid, lauric $\operatorname{acid}^{21}$ and organosulphate anionic surfactant, sodium dodecyl sulfate (SDS) for the deduction of cationic dye "methyl violet" from the aqueous solution $^{22}$. Effect of variation in $\mathrm{pH}$, SDS concentration and ionic strength was also studied. Sodium dodecyl sulfate was also used to engineer the surface of MNPs to estimate the deduction of safranin $\mathrm{O}$ dye from an aqueous solution ${ }^{23}$.<smiles>Cc1cc2nc3cc(C)c(N)cc3[n+](-c3ccccc3Cl)c2cc1N</smiles>

\section{Safranin O Dye}

Fig.-1

Modification of Chitosan-coated MNPs has been reported to improve their adsorption capacity. Ethylenediamine modified chitosan-coated MNPs were used for the adsorption of acidic dyes from aqueous solutions. ${ }^{24}$

Another, magnetic bio sorbent i.e. magnetic peach gum bead (MPGB) was synthesized by linking the magnetic nanoparticles with peach gum. ${ }^{25}$ These nanoparticles were simultaneously displayed admirable adsorption properties for cationic dyes. The overall study revealed that these nanoparticles can be used as an effective and environment-friendly adsorbent. Cetyltrimethylammonium bromide (CTAB), an organic bromide salt and a surfactant have also been used for the surface modification of MNPs. ${ }^{26}$ The influence of numerous parameters such as $\mathrm{pH}$, surfactant amount, sorbent amount and ionic strength on the adsorption of dyes was also studied. A significant decrease in adsorption with the increase in the salt concentration $(\mathrm{NaCl})$ was observed. The increased amount of salt may have lowered the electrostatic interactions between magnetic nanoparticles, analyte and CTAB molecules. A new nanocomposite, $\mathrm{Fe}_{3} \mathrm{O}_{4}$-TSPED-Tryptophan (FTT) was prepared ${ }^{27}$ for the adsorption of Congo-Red dye. Bare magnetite nanoparticles were prepared using the co-precipitation method. The black $\mathrm{Fe}_{3} \mathrm{O}_{4}$ nanoparticles were 
RASĀYAN J. Chem.

Vol. 14 | No. 2 |829-835| April - June | 2021

treated with $\mathrm{N}$-[3-(Trimethoxysilyl)propyl]-ethylenediamine (TSPED) to form $\mathrm{Fe}_{3} \mathrm{O}_{4}$-TSPED. These modified magnetite nanoparticles were treated with tryptophan to form $\mathrm{Fe}_{3} \mathrm{O}_{4}$-TSPED-Tryptophan. These functionalized nanocomposites were used as adsorbents for the degradation of Congo-Red dye. The adsorption efficiency was investigated by varying several parameters including $\mathrm{pH}$, dye concentration etc. This work suggested that the reported functionalized nanocomposite may be employed as an efficient tool for water treatment.<smiles>N#[N+]S(=O)(=O)c1ccc(N=Nc2c(O)ccc3ccccc23)cc1</smiles>

Acid Orange 7<smiles>O=C1C=Cc2cc([As])cc([As])c2/C1=N\Nc1ccccc1</smiles>

Acid Orange 10

Fig.-2

\section{Surface Functionalization using Inorganic Molecules}

Many researchers have reported the surface-modified nanoparticles having an inner core of iron oxides and an outer covering of inorganic materials e.g. metals like silica, gold and gadolinium. Such metalcoated IONPs not only offer stability to the nanoparticles in the solution but also help them to bind with various biological ligands. This property has been utilized in the elimination of dyes from water. Hexadecyl functionalized magnetic silica nanoparticles were prepared $\left(\mathrm{C}_{16} / \mathrm{SiO}_{2}-\mathrm{Fe}_{3} \mathrm{O}_{4}\right)$ for the removal of dye "Rhodamine 6G" under various experimental conditions. ${ }^{28}$ For adsorption experiments, the optimum $\mathrm{pH}$ was found to be 11.00 . Adsorption isotherm studies were observed to be following the Langmuir isotherm model. The adsorption kinetics was found to be in good agreement with pseudosecond-order kinetics. Ionic liquid (IL) was used for surface functionalization of magnetite nanoparticles having $\mathrm{Fe}_{3} \mathrm{O}_{4} @ \mathrm{SiO}_{2}$ core to facilitate the adsorption of reactive yellow 15 dye from waste water. ${ }^{29}$ The $\mathrm{Fe}_{3} \mathrm{O}_{4} @ \mathrm{SiO}_{2} @ \mathrm{IL}$ nanoparticles were found to have a remarkable capacity to trap the reactive yellow 15 dye from wastewater. Kinetic data suggested the pseudo-second-order reaction mechanism.

Table-1: Various Coating Materials and Methods of Synthesis, used to Study the Sorption of Dye Effluents

\begin{tabular}{c|l|l|l}
\hline S. No. & Coating Material & $\begin{array}{l}\text { Method of } \\
\text { synthesis }\end{array}$ & Dye adsorbed \\
\hline 1. & Polyacrylic acid (PAA) & Co-precipitation & Methylene Blue \\
\hline 2. & Poly-glutamic acid (PGA) & Co-precipitation & Methylene Blue \\
\hline 3. & APTES-AA@Co@CA & Co-precipitation & $\begin{array}{l}\text { Crystal Violet, Methylene Blue, } \\
\text { Alkali Blue 6B }\end{array}$ \\
\hline 4. & O-carboxymethylchitosan-n-lauryl & Co-precipitation & Remazol Red 198 \\
\hline 5. & PolyMETAC & Co-precipitation & Alizarin Red S \\
\hline 6. & Chitosan & Co-precipitation & Blue 19 \\
\hline 7. & Polypyrrole & Co-precipitation & Alizarin Yellow GG \& Alizarin Red-S \\
\hline 8. & Poly(styrene-co-methacrylic acid) & Co-precipitation & Crystal Violet \& Rhodamine B \\
\hline 9. & PEG & Hydrothermal & Methyl Orange \\
\hline 10. & Fe $\mathrm{O}_{4} @$ SiO -MPS-g-AA-AMPS & Solvothermal & Methylene Blue \\
\hline 11. & CMC & Co-precipitation & Methylene Blue \\
\hline 12. & Lignin biopolymer & Co-precipitation & $\begin{array}{l}\text { Methylene Blue, Cibacron Blue \& } \\
\text { Remazol Red. }\end{array}$ \\
\hline 13. & Lauric acid & Co-precipitation & Methyl Violet \\
\hline 14. & SDS & Co-precipitation & Methyl Violet \& Safranin O \\
\hline & \multicolumn{2}{l}{833} &
\end{tabular}


RASĀYAN J. Chem.

Vol. 14 | No. 2 |829-835| April - June | 2021

\begin{tabular}{c|l|l|l}
\hline 15. & $\begin{array}{l}\text { Ethylenediamine modified chitosan- } \\
\text { coated MNPs }\end{array}$ & Microemulsion & Acid Orange 7 \& Acid Orange 10 \\
\hline 16. & MPGB & Co-precipitation & Methylene Blue \\
\hline 17. & CTAB & Co-precipitation & Nyloset Yellow E-RK \\
\hline 18. & FTT & Co-precipitation & Congo-Red \\
\hline 19. & $\begin{array}{l}\text { Hexadecyl functionalized magnetic } \\
\text { silica nanoparticles }\end{array}$ & Solvothermal & Rhodamine 6G \\
\hline 20. & Ionic liquid & $\begin{array}{l}\text { Co-precipitation } \\
\text { followed by } \\
\text { solvothermal }\end{array}$ & Reactive Yellow 15 \\
\hline
\end{tabular}

\section{CONCLUSION}

Nanoadsorbents are being used as a potential tool for the degradation of colored pollutants from contaminated water. Among these nano adsorbents, surface-functionalized magnetite nanoparticles have become more popular due to their large surface area to volume ratio and ease of separation from water by their magnetic property. Surface functionalization of magnetite nanoparticles with polymeric, nonpolymeric, inorganic and protein molecules have been described for the efficient deduction of dyes from the aqueous solution. To recapitulate, surface fabricated magnetic iron oxide nanoparticles can be used as an eco-friendly and efficient tool for the sorption of dye components from the wastewater.

\section{ACKNOWLEDGMENT}

Co-authors, Arti Jangra and Jaiveer Singh are grateful to UGC, New Delhi (Govt. of India) for providing necessary funds in the form of a Junior Research Fellowship. Authors are obliged to the Department of Chemistry, Kurukshetra University Kurukshetra for providing research laboratory and other research facilities.

\section{Abbreviations:}

MNPs: Magnetite nanoparticles, IONPs: Iron oxide nanoparticles, PAA: Polyacrylic acid, PGA: Polyglutamic acid, APTES-AA@Co@CA: 3-aminotriethoxysilane and copolymer acrylic acid and crotonic acid, PolyMETAC: [2-(methacryloyloxyl) ethyl] trimethylammoinum chloride, PEG: Polyethylene glycol, AA: Acrylic acid, AMPS: 2-acrylamido-2-methyl-1-propanesulfonic acid, CMC: Carboxymethyl cellulose, SDS: Sodium dodecyl sulfate (SDS), MPGB: Magnetic peach gum bead, CTAB: Cetyltrimethylammonium bromide, ZFN: zinc ferrite nanoparticles, TSPED: N-[3(Trimethoxysilyl)propyl]-ethylenediamine, FTT: $\mathrm{Fe}_{3} \mathrm{O}_{4}$-TSPED-Tryptophan, IL: Ionic liquid

\section{REFERENCES}

1. N.M. Mahmoodi, Journal of Chemical and Engineering Data, 56(6), 2802(2011),DOI: 10.1021/je101276x

2. B.B.T. Patil, Journal of Advanced Chemical Engineering, 5, 131(2015), DOI:10.4172/20904568.10001.31

3. J. Wang and C. Chen, Biotechnology Advances, 27(2), 195(2002),DOI: 10.1016/j.biotechadv.2008.11.002

4. A. Jangra, J Singh, K. Rani, J. Kumar, P. Kumar and R. Kumar, Rasayan Journal of Chemistry, 13(4), 2266 (2020), DOI:10.31788/ RJC.2020.1346081

5. U. Schwertmann and R. Cornell, Iron oxides in the laboratory. VCH Publ. Inc., New York (1991).

6. J. Singh, A. Jangra, J. Kumar, K. Rani and R. Kumar, Rasayan Journal of Chemistry, 13(1), 105 (2020), DOI:10.31788/RJC.2020.1315382

7. Z.H. Zhou, J. Wang, X. Liu and H.S.O. Chan, Journal of Materials Chemistry, 11(6), 1704(2001) DOI: $10.1039 / \mathrm{b} 100758 \mathrm{k}$

8. Z.J. Zhang, X.Y. Chen, B.N. Wang and C.W. Shi, Journal of Crystal Growth, 310(24), 5453(2008), DOI: 10.1016/j.jcrysgro.2008.08.064

9. S.Y. Mak and D.H. Chen, Dyes and Pigments, 61(1), 93(2004), DOI:10.1016/j.dyepig.2003.10.008

10. B. Stephen Inbaraj and B.H. Chen, Bioresource Technology, 102(19), 8868(2011), 
RASĀYAN J. Chem.

Vol. 14 | No. 2 |829-835| April - June | 2021

DOI: 10.1016/j.biortech.2011.06.079

11. F. Ge, H. Ye, M.M. Li and B.X. Zhao, Chemical Engineering Journal, 198-199, 11(2012), DOI:10.1016/j.cej.2012.05.074

12. C.A. Demarchi, A. Debbrassi, F. de Campos Buzzi, N. Nedelko, A. Slawsk-Waniewska, P. Dluzewski, J. Dal Margo, J. Scapinello and C.A. Rodrigues, Arabian Journal of Chemistry, 12(8), 3444 (2019), DOI: 10.1016/j.arabjc.2015.08.028

13. S. Hanif and A. Shahzad, Journal of Nanoparticle Research, 16(6), 1(2014), DOI:10.1007/s11051014-2429-8

14. V.C. Nguyen, Q.H. Pho, K.Z. Elwakeel and D. Fu, The Scientific World Journal, 10, 273082(2014), DOI: $10.1155 / 2014 / 273082$

15. M.B. Gholivand, Y. Yamini, M. Dayeni, S. Seidi and E. Tahmasebi, Journal of Environmental Chemical Engineering, 3(1), 529(2015), DOI:10.1016/j.jece.2015.01.011

16. M. Hayasi and M. Karimi, Polymer Bulletin, 74(6), 1995(2017), DOI:10.1007/s00289-016-1816-y

17. S. Natarajan, V. Anitha, G.P. Gajula and V. Thiagarajan, ACS Omega, 5(7), 3181(2020), DOI:10.1021/acsomega.9b03153

18. X. Zheng, H. Zheng, R. Zhao, Y. Sun, Q. Sun, S. Zhang and Y. Liu, Materials, 11(8), 1312(2018), DOI: $10.3390 / \mathrm{ma} 11081312$

19. M. Zirak, A. Abdollahiyan, B. Eftekhari-Sis and M. Saraei, Cellulose, 25(1), 503(2018), DOI: $10.1007 / \mathrm{s} 10570-017-1590-5$

20. C.E. de Araújo Padilha, C. da Costa Nogueira, D.F. de Santana Souza, J.A. de Oliveira and E.S. dos Santos, Industrial Crops and Products, 146, 112167(2020), DOI:10.1016/j.indcrop.2020.112167

21. Y. Sahoo, H. Pizem, T. Fried, D. Golodnitsky, L. Burstein, C.N. Sukenik and G. Markovich, Langmuir, 17(25), 7907(2001), DOI:10.1021/LA010703+

22. F. Keyhanian, S. Shariati, M. Faraji and M. Hesabi, Arabian Journal of Chemistry, 9, S348(2016) DOI: 10.1016/j.arabjc.2011.04.012

23. S. Shariati, M. Faraji, Y. Yamini and A.A. Rajabi, Desalination, 270(1-3), 160(2011), DOI: $10.1016 / j . d e s a l .2010 .11 .040$

24. L. Zhou, J. Jin, Z. Liu, X. Liang and C. Shang, Journal of Hazardous Materials, 185(2-3), 1045 (2011), DOI:10.1016/j.jhazmat.2010.10.012

25. C. Li, X. Wang, D. Meng and L. Zhou, International Journal of Biological Macromolecules, 107, 1871 (2018), DOI:10.1016/j.ijbiomac.2017.10.058

26. N. Dalali, M. Habibizadeh, M. Khoramnezhad, and M. Faraji, In Proceedings of International Conference on Environmental and Agriculture Engineering IPCBEE, 15, 89 (2011).

27. J.K. Sahoo, S.K. Paikra, M. Mishra and H. Sahoo, Journal of Molecular Liquids, 282, 428(2019) DOI: 10.1016/j.molliq.2019.03.033

28. Y.P. Chang, C.L. Ren, Q. Yang, Z.Y. Zhang, L.J. Dong, X.G. Chen and D.S. Xue, Applied Surface Science, 257(20), 8610(2011), DOI:10.1016/j.apsusc.2011.05.031

29. F. Golmohammadi, M. Hazrati and M. Safari, Microchemical Journal, 144, 64(2019) DOI:10.1016/j.microc.2018.08.057

[RJC-6207/2020] 